IDEA - Studia nad strukturą i rozwojem pojęć filozoficznych XXVIII/2

Białystok 2016

\title{
FRANKLYN EGWALI
}

(Benin, Nigeria)

\section{THE INTRICACIES OF BENIN BEAD MOTIFS - THEIR PLACE IN CONTEMPORARY NIGERIAN ART}

\section{Introduction}

An appraisal of Benin art is an appraisal of the popular Igbo Ijele mask that possesses more than 1,500 mask motifs. And each motif has pattern, sections and subjections. Again, these sections also can be appraised from various transmogrified nuances, almost like an elephant meat that cannot be consumed in a full swing because of its monumentality and sheer colossal nature and stature.

Benin art is popular, significant and profound as a result of so many illuminating nuances and expressiveness. From available records and research, it is partly as a result of its detailed finishing, motifs realization, definition and application. How do Benin motifs and their artistic filament and accoutrement contribute to the popularity of its arts and culture? This is the onus of this paper. Over the years, Benin art keep reverberating and reechoing as a result of its definitive, cognative and rapacious concordant concepts. These profound concepts teaches nearly all the various strata and segments of their entire life, from natural to supernatural, realism to complete abstractism and perhaps, 
surrealism and stylization. In all these variegated concepts, we can still tie these concepts into various headings and themes - bracelets, staff of office, handheld clappers, ivory trumpets, ivory containers and implements, brass vessels and traditional accoutrements, court and ceremonial objects, wood boxes, tool and chairs, the ornaments, pendants, bells, roosters, heads of obas, and queen mother heads. Even as we have tried here to itemize these artworks, each item can still be subdivided into various subsections. But for the purpose of brevity, we shall divide this analysis and appraisal into BRONZE HEADS, BEAD MOTIFS, and their PENETRATING MOTIFS. All these motifs form what we call Benin essential motifs.

\section{Bead motifs of the Benin bronze heads}

One of the commonest pieces of Benin artforms is their bronze heads. They are exquisitely and delicately molded and casted to profoundly reflect the spendour, grandour, royalty and authority of the Oba whom the Binis called god. From observation, one definite feature that runs from the fountain of the head to the shoulder is the Coral Beads. These traditional accoutrements are part of the trappings that make up the costume of the $\mathrm{Oba}$ and sometimes his wives. According to Dark (1973) and Ezra (2005), this is so because of the significance of the beads to royalty in Benin culture and tradition.

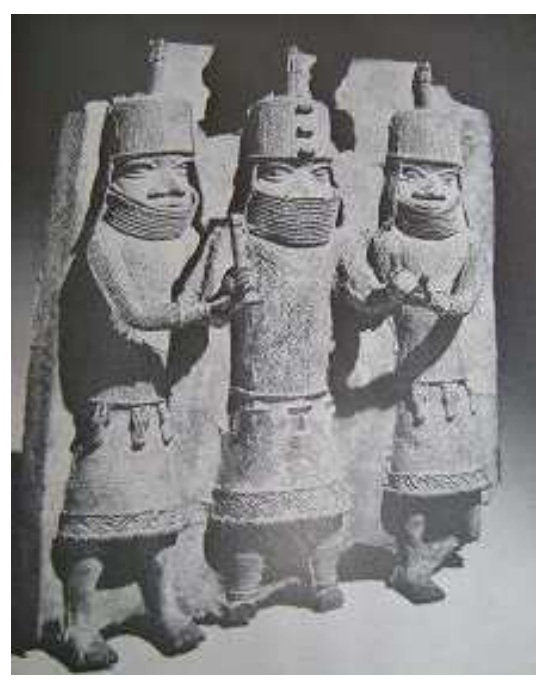

Fig. 1, The Oba being held on the hands by his very senior chiefs. Beads have been used lavishly for his dress and crown 


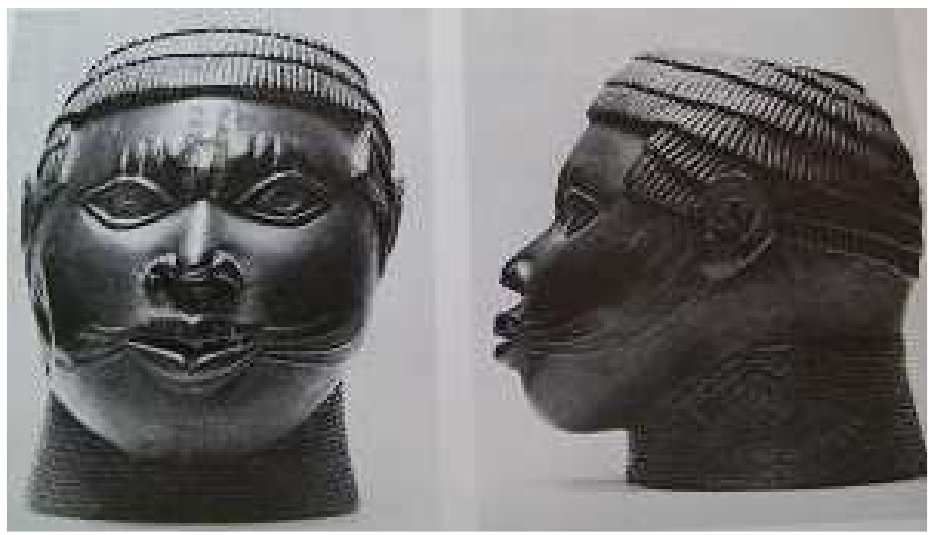

Fig. 1b, Omonoba wearing his crown in ancient time.

The crown is made of coral beads.

\section{Significance of the Beads}

In ancient times, according to Izevbigie (a former commissioner for Arts and Culture, Edo State and past Head of Department of Fine and Applied Arts, University of Benin and an art historian), all coral and stone beads are owned by the Oba. They are distributed by him to chiefs, titleholders, and numbers of place associations but must be returned to him upon the death of the holder of the beads. Furthermore, it is only the Oba that wears a complete costume of beads, including crown, colar (as observed in Fig. 1, $2 \& 3$ ), robe and even shoes. According to Izevbigie, the beads are not merely decorative but are imbued with divine authority and power. Indeed, the importance of the beads to the palace and by extension to the Benin people cannot be overemphasized. They are said, as posited by Chief Henry Igiehon, in an interview in Benin, to have been brought from the sea god - Olokun. However, from the fifteenth and sixteenth century on, part of the article of trade between the Benins and the Portuguese were coral beads. In fact, as concluded by Izevbigie, in their form, content and critical subject matters, the beads poignantly explore and add essence and credence to the divine nature and stature of the Oba. The relationship of the Oba with his people and courtiers, 
the splendid deeds of his ancestors and the grandeur and sovereignty of the palace could also be gleaned and extracted from the beads which the king (Oba) have used in enveloping and encapsulating himself in a show of royalty, majesty and nobility.
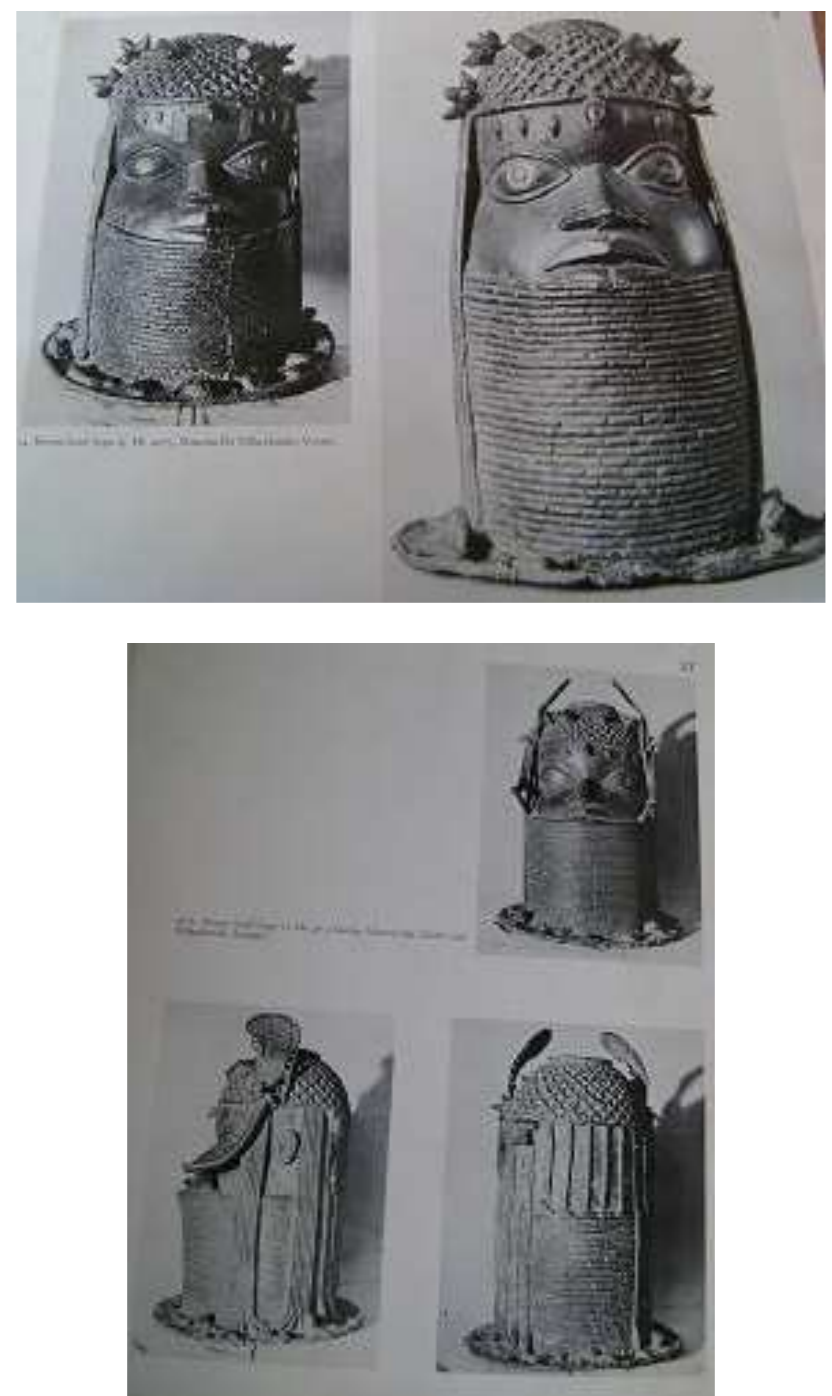

Fig. 2 and 3 showing the Oba in a contemporary crown.

Here we observe the ceremonial sword used as projections on the sides of the crown. 


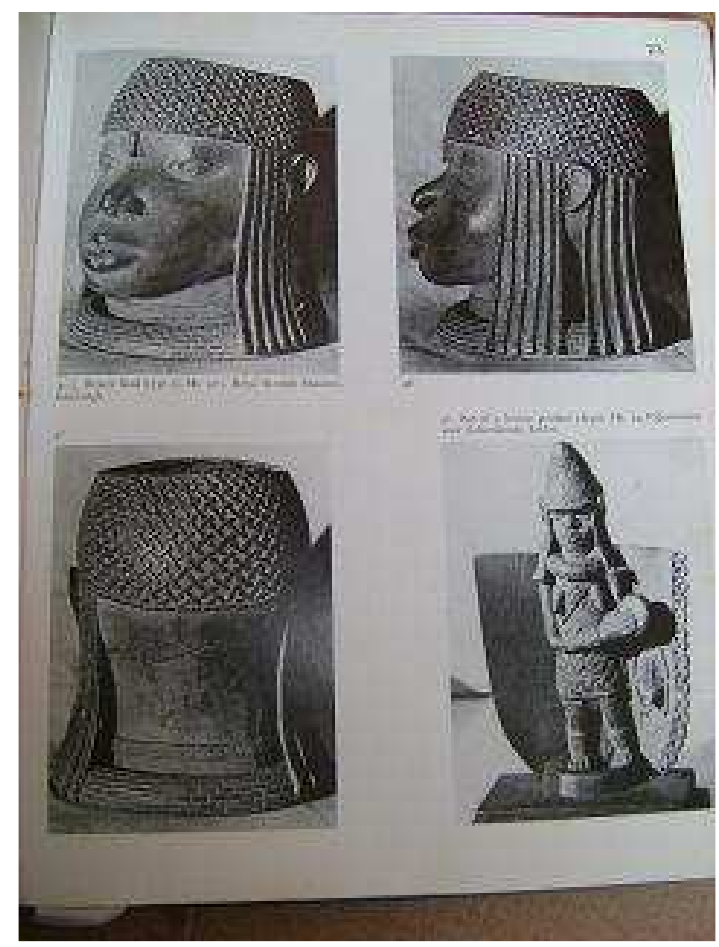

Fig. 3b, showing the ancient style of the Oba's crown.

At the sides we can see some beads loosely extending from the ear to the shoulder.

\section{Appraising the Beaded Bronze Heads (Fig. 1, 2, 3 \& 4)}

In appraising all the bronze heads, it is petinent to mention that they all appear the same except for some unique differences here and there. For instance in Fig. 1, we observe a simple crown, like a cap over the head with some of the bead strands hanging down the side of the head and reaching the shoulders. While the arrangement of the beads on the head (the crown) is crisscrossed, the arrangement of the bead on the neck (collar) is orderly following the beadlike pattern. Although the royal expression is rather tense and resolute, this did not remove the naturalness of the sculpture. But Fig.2 and 3 is a far departure from Fig. 1. In design, in context, contour and texture, Fig. 2 and 3 according to Izevbigie is a more complex and contemporary design as crown for the Oba. 
The projections on the two sides of the crown are said to represent the ceremonial swords, ada, which is restricted to the Oba and the highest ranking chiefs. Again, a critical appraisal will reveal a curving archs of beads strung on a wire in front of the eyes, in the words of Izevbigie, these can also be known as "spectacles". Indeed, all these far-reaching and penetrating configuration and conceptualization add to the eminence, magnificence and impressiveness of the crown and the Oba himself.

Not to be forgotten or overlooked in a hurry is the part beads have played in this noble inventiveness. In this project, the artist has been able to use the bead motifs to adroitly uplift the meaning and significance of the royal crown. Here, various dimensions and volumes of the bead were deployed and at the end we can safely lay claim to six shapes of beads all weaved together to form an exciting and fascinating diadem for the Oba. According to Sweet Ebeigbe (a senior art teacher in the Department of Fine and Applied Arts, University of Benin and herself a Princess from the royal house of Benin Kingdom), there are specific guilds known as Guild of Beadmakers, their function is to weave beads for the Oba's costumes from the Oba's crown to his beaded shoes. It is necessary to assert here that the costume of the Oba (don't forget my father was Oba Akenzua II (18 to 1979) in some ceremonial occasions is extremely elaborate and could weigh heavily on him. These costumes made mainly of coral beads are his coral crown, with its wings, the coral choker, the coral shirt, coral pendants, the large necklaces, the medicines, the coral ornaments on his chest, even the ivory pendants suspended round his waist, ivory armlets all made him resplendent, dazzling, regal, magnificent, divine, but according to Dark (1973), it is a divinity among men. 


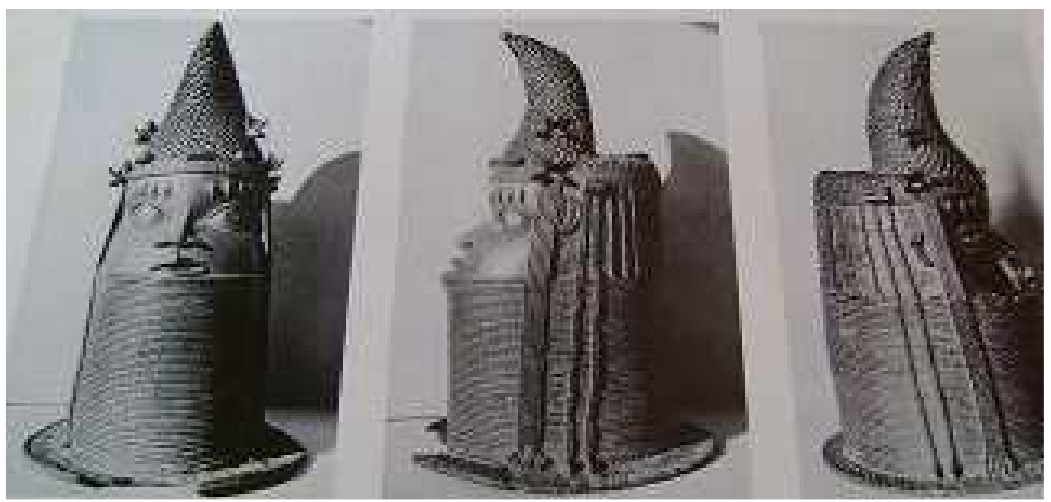

Fig. 4, The Ancient crown of the Queen Mother.

Here, it is showing the adroit weaving together of beads to emphasis the uniqueness of the crown of the queen.

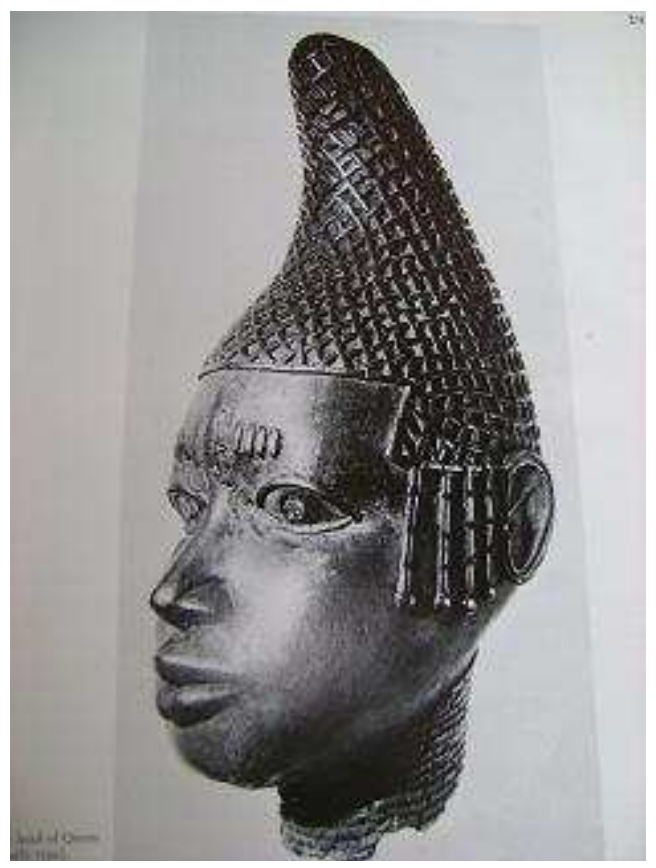

Fig. 5, The Queen Mother with her contemporary time. 


\section{Appraisal Fig. 4 and other Queen Mother Bronze Heads}

The Oba bronze heads are not the only bronze heads that are popular and important among the corpus of bronze heads in Benin kingdom. The Queen Mother heads are also very distinguished, distinct, and characteristically outstanding in Benin art. Why are they exceptionally famous, extraordinary and unmistakably profound and significant among other artforms in an exhibition? For one, according to Kennedy (2005), it has to do with the adroitness and ingenuity that is brought to bear in the manipulation and configuration of the bead motifs itself. Attention and devotion is seriously paid to details and relationship of one form to another. As stated by Agbontaen (1990), the queen mother started to be popular and well known as a result of what the mother of Oba Esigie did for her son. As posited by Egwali (2004), she became the rock, foundation and defence of the son's royalty and nobility. She frequently fought battles for Oba Esigie, had troops (soldiers) under her command, therefore to commemorate and celebrate this achievement, the Iyoba (queen mother title and visibility started to be well known) title was introduced around the 16th century by Oba Esigie.

\section{A Critical X-ray of the Iyoba Bronze Head}

As noted by Ighile (2002), Bryna (1999) and Chika (1988), the queen mother's head is distinguished as an African artform as a result of some definite characteristics. These include the coral bead crown with a high, forwardpointing peak, an elongated version of an elaborate coiffure known as chicken's beak. Normally this is worn by the queen mother or very high ranking Edo women. According to Amos (1995) and Paula Amos (1990), the projection of the head of the queen mother crown as we observe in Fig. is called ede iyoba by the Benins. It can also be likened to the crown of the Oba himself. It is poignant to assert here and now that the right to put on a coral-beaded crown is 
limited to the Oba, the queen mother and sometimes the Ezomo who is the number one war chief. As can be observed from the figure, the queen mother's bronze head is poignantly different from the Oba's bronze heads, in that the queen bronze head does not possess the figure attached to the side of the crown that resemble the traditional sword and the projection that is in front of the Oba's bronze head itself which is called the "spectacle". As stated by AigImokhuede, while the queen's bronze head is elegant, graceful and classical in finishing, the Oba's bronze heads appear rather blunt, rugged, boisterous, severe and shaggy in nature and contour. Perhaps, this is as a result of the office of the Oba himself as a warrior king. While only one strand of coral bead run around the Oba's head just before the crown, the queen mother's own is made up of between four and five strands. Again, all these add more grace and elegance to the queen mother's bronze head. This grace can be seen very clearly from the older concept of Iyoba's crown. In this type, we observe a crown flowing gracefully from the top or tip of the crown to the tempo of the head with some four coral beaded strands loosely dangling from the side of the ear almost reaching the chin of the queen mother herself. But as time progressed, "the chicken beak" type was introduced as part of the ede iyoba (Iyoba's crown) which has continued to hold sway in contemporary time.

\section{Conclusion}

No doubt, the Benins have this likeness for beads and any craft or art which it is used for. As can be appraised from the queen mother's bronze head, a lot of transformations have taken place from the earlier time to this contemporary period. Before this period, it is the more subtle, graceful queen mother bronze head that was in vogue but starting from the 17th and 18th century, the more forceful, rugged type took the centre stage. This second group of queen mother's head exceptionally looks like the Oba's bronze heads. According to Aig-Imuokhuede (1988), these heads are large, thick walled and is of heavy casting. As stated by Egwali (2004), they possess the high cylindrical 
bead collar that comes up to the solid and firm mouth. Looking at the top of the head, as stated by Bardi (2004), they have a semi-circular openings; this is to enable them insert ivory tusk like the Oba bronze heads at the alter.

Another very unique similarity between the Oba's bronze heads and that of the queen mother is that on the heads of the Obas, the lower part of the face ballons outward, and yes, in laid with iron irises, they are equally and dramatically exaggerated, heavy and the eyeball look frightening, charged and rugged. As a result of Benin love for beads, as clearified by Odutokun (1992), it is lavishly, profusely and indeed extravagantly used in most of their bronze artforms especially the bronze heads.

In contemporary times, many artists have used the beads as motifs in their various artistic creations. Shortly before his death, one of African finest and prolific sculptor, Ben Osawe, made allusions to bead as an outstanding motif in his visual configuration. In his words,

It is an artistic heritage which is still very much appreciated or highly priced in this contemporary time. In most of my final sculptures, I used the bead motif to situate the visual expression as caving from Africa. They infact add to the quintessential nature and stature of the art piece.

Other African artist of Benin extraction that have popularized the bead motif include such names as Princess Sweet U. Ebeigbe (1958-), Ben Osawe (1931-2007), Erabor Emokpae (1934-1987), Isiaka Osunde (1936-), Ovia Idah (1897-1968), Dada Osazuwa (1936-1998), Elizabeth Olowu (1945-), and Alfred Izevbigie (1942-). All these artists - sculptors, painters, ceramics, and graphic artists allow the bead motifs to constantly reverberate resoundingly in their works of art to the great admiration and appreciation of the appreciative audience.

According to Freeborn Odiboh in an interview in Benin, in Benin traditional marriage ceremonies, the bride and groom are proudly observed decking themselves with beads. It is used as head decoration for the pride, like those of the queen mother in ancient times. Occasionally, their necklaces, 
wristlet, hand bags, anklelet are all made of beads. While many are crazy about using purely coral breads in their dress essence, others are very comfortable combining it with pure gold as it further add prestige, distinction and classified importance to the dressing and grooming.

At other times, the Oba is observed giving out rare coral breads to some of his subjects who have distinguished themselves in one way or the other. Therefore, as man continue to live, the importance and usage of beads in Benin Kingdom will continue to glow and grow as we find ourselves beginning to value our cultural heritage - a heritage that is vibrant, dynamic, forceful, quintessential, energetic and dazzling in assertion, articulation and appreciation.

\section{Summary}

Beads have been part of the traditional dress essence of the Africans and other popular cultures of the world. Benin art is phenomena and generally accepted worldwide partly as a result of their resounding uniqueness, peculiarity and exceptional finishing of delicate forms especially those bordering on beads. These beads are used for the making of the Oba's diadem, dresses and shoes. Some of his flywhisks are made of beads too. In contemporary time, and even in ancient period, the Oba beaded crown continue to evolve to the extent that the style of crown worn then is different from those in vogue today. The Queen Mother's beaded crown has also gone through some significant changes and processes. Today, what we have is a profoundly gracious and courtly beaded crown. What are the other outstanding importance and weighty functions of the bead to the Benin man and woman and by extension to other popular cultures and traditions of the world? This is what this paper has unearthed, critically appraised and established.

Key words: African culture, art, tradition, space

\section{Bibliography}

Albert Kosetenevich (2000) Hidden Treasures Revealed. Harry N. Abrahams Inc, NY, USA.

Andre Magnun (2000) Contemporary Art of Africa. Great Clarendon Street, Oxford OX2 6DP, UK. 
David Hopkins (2001) After Modern Art 1945 - 2000. Great Claredon Street, Oxford OX26 DP, UK.

Edward Lucie-Smith (2000) Sexuality of Western Art. Thames and Hudson World of Art, 181A High Halborn, London WCIV 7QX.

Franklyn Egwali (2004) Song of the Benin Carver. Nigerian Crafts and Techniques, Nigerian Crafts Forum - Department of Industrial Design, Federal University of Technology, Akura, Nigeria, pp. 114-121.

Franklyn Egwali (2005) A Journal of the Arts, Vol. 3, Department of Fine and Applied Arts, University of Benin, Benin City, pp. 30-37.

Franklyn Egwali (2006) Sculptures and Motifs of Great Benin Kingdom. Journal of Vocational Science and Educational Development (JOVSED) Vol. 7, No. 1 \& 2, pp. 28-34.

Franklyn Egwali (2006) Creativity and Stylistic Sculptures in Nigeria: A Study of Ben Osawe's Sculptural Monuments - African Journal of Interdisciplinary Studies. An International Journal of Research Studies in Multidimensional Field. Pp. 74-80.

Franklyn Egwali (2006) An Appraisal of the Conceptual, Thematic and Photographic Language of the Art of Ogene John. ELA - Journal of Africa Sudies, No. 19 \& 20, Department of Fine and Applied Arts, Faculty of Environmental Science, Ladoke Akintola University of Technology, Ogbomosho, Nigeria, pp. 61 - 71, May/Oct. 2006.

Franklyn Egwali (2008) The Criticality and Equanimity of Ben Osawe's Linear Visual Expression. Knowledge Review: A Multidisciplinary Journal. Vol. 16, No. 2, pp. 63-73.

Franklyn Egwali (2007) An Appraisal of Dexterity and Creativity in Osawe's Plaster of Paris (PoP) Casting and Clay Modelling. ELA - A Journal of African Studies, No. $21 \& 22$. Department of Fine and Applied Arts, Faculty of Environmental Science, Ladoke Akintola University of Technology, Ogbomosho, Nigeria, pp. 9-23.

Jean Kennedy (2004) New Current Ancient Rivers. Contemporary African Artist in a Generation of Change. Washington and London: Smithsonian Institute Press.

John Jocobus (2000) Modern Art. Thames and Hudson Inc, 500 Fifth Avenue, New York 10110, USA.

Nikalous Pervsner (2001) The Sources of Modern Architecture and Design. Thames and Hudson World of Art, 181A High Halborn, London WCIV 7QX.

Patrick Walberg (2003) Surrealism. Thames and Hudson World of Art, 181A High Halborn, London WCIV 7QX.

Penelope Curtis (2001) Sculpture 1900-1945. Oxford History of Art, Oxford University Press, Great Clarendon Street, Oxford OX2 6DP, UK.

Ron Bowen (1992) Drawing Master Class. The Slades School of Fine Art. Little Brown and Company Limited, Canada.

William Rubin (2001) Primitivism in the 20th Century Arts. The Museum of Modern Art, New York, 11 West 53 Street, NY 1000191, USA. 


\section{Interviews}

Dr Omokaro Izevbigie was a former Commissioner for Arts and Culture (Edo State) and former Head of Department, Fine and Applied Arts Department, University of Benin. He was interviewed on the profound significance of bead in Benin art and culture, in his office on the 25th of April, 2006.

Chief Henry Igiehon is a traditional bronze caster and ceramist in Fine and Applied Arts Department, University of Benin. He was interviewed on the bead making in Benin tradition in his house at No. 17, Ozigbo Street, Benin City, on the 15th of May, 2007.

Dr. Sweet Ebeigbe is a Senior Ceramics Lecturer in the Department of Fine and Applied Arts, University of Benin. She is a Princess from the royal family of Benin. She was interviewed on the making of shoes, crown and dress with beads in Benin. Interview was in her office in Benin on the 29th of June, 2007.

Dr. Freeborn Odiboh, is a Senior Lecturer of Art History in the Department of Fine and Applied Arts, University of Benin. He was interviewed on the place of bead in the traditional dressing of the bride and groom in Benin art and culture. The interview was in his office on the 27th of May, 2007.

Franklyn Egwali

Lecturer, Department of Fine and Applied Arts, University of Benin, Niegeria. 